VIEWPOINT

\title{
Inter-Regional Medical Cooperation in the Caribbean: Lessons from the Ongoing Cooperation between Martinique, St Lucia, and Dominica \\ D Resiere ${ }^{1}$, R Valentino ${ }^{1}$, H Lucron $^{2}$, JR Daniel ${ }^{3}$, M Didier ${ }^{3}$, K Compton ${ }^{1}$, M Spence ${ }^{1}$, B Megarbane ${ }^{4}$, F Roques $^{2}$, H Mehdaoui $^{1}$
}

\begin{abstract}
Recently, Martinique was accepted as an associate member by the Council of Ministers of the Organization of Eastern Caribbean States. This membership constitutes a major asset in bringing Martiniquais closer to the other Caribbean populations and should play a key role as it relates to regional cooperation especially in the domain of healthcare. It is urgent for professionals in the Caribbean to discuss the possibilities of improving relationships between countries in training, development and continuous medical education. Cooperation between the French Caribbean departments and surrounding countries appears to be quite indispensable.
\end{abstract}

Keywords: Caribbean, inter-regional cooperation, medical collaboration

WIMJ Open 2014; 1 (1): 26

\section{INTRODUCTION}

When Martinique applied for membership of the Caribbean Economic Community (CARICOM) in July 2012, it was both a rare and joyful event. Martinique had been trying to enter different regional organizations for a long time, including the CARICOM, the Forum of the Caribbean Group of African, Caribbean and Pacific States (ACP), and the Organization of Eastern Caribbean States (OECS).

Recently, Martinique was accepted as an associate member by the Council of Ministers of the OECS. This membership constitutes a major asset in bringing Martiniquais closer to other Caribbean populations and should play a key role as it relates to regional cooperation, especially in the domain of healthcare.

For decades, the status of patients from neighbouring islands hospitalized in the French overseas departments has been impacted by both stereotypical and contradictory images. Future true cooperation will help to redefine these images and create a formidable partnership that will be in the best interest of all patients. Cooperation between the French

From: ${ }^{1}$ Centre Hospitalier Universitaire, Fort-de-France, Martinique, French West Indies, France, ${ }^{2}$ Service de Chirurgie Cardiothoracique, Fort-deFrance, Martinique, French West Indies, France, ${ }^{3}$ Cardiology Department, Tapion Hospital, Castries, St Lucia, West Indies and ${ }^{4}$ Réanimation Médicale et Toxicologique, Hôpital Lariboisière, INSERM U1144, Université ParisDiderot, Paris, France.

Correspondence: Dr D Resiere, Centre Hospitalier Universitaire, Fort-deFrance, Martinique, French West Indies, France. Fax: +33-596-758-476, e-mail: dabor.resiere@chu-fortdefrance.fr
Caribbean departments and surrounding countries appears to be in demand (1).

\section{Health facilities in Martinique}

Martinique is part of the Lesser Antilles, situated in the Eastern Caribbean. It is bordered to the east by the Atlantic Ocean and to the west by the Caribbean Sea. The closest neighbours are two English-speaking islands, Dominica to the north and St Lucia to the south. Its population is about 399000 , according to the 2010 census, for $1128 \mathrm{~km}^{2}$ surface area $(60 \mathrm{~km}$ length and $30 \mathrm{~km}$ width).

Martinique has twelve public hospitals and seven private clinics. The two major clinics are St Paul and St Marie. The major hospital, University Hospital of Martinique (UHM) is made up of three hospitals (Pierre Zobda Quitman University Hospital, Mangot-Vulcin General Hospital and Trinité General Hospital). The UHM is the largest French-speaking university hospital in the Caribbean, consisting of 1600 beds including 680 medical and 273 surgical beds. The UHM is well-equipped with multiple resources, making it eligible for medical cooperation on a Caribbean level.

Healthcare cooperation between Martinique and St Lucia France's first major contribution to healthcare management in St Lucia was recorded in 1992 with the handing over of a complete Obstetrics and Gynaecology wing at Victoria Hospital. Prior to this historic event, technical/scientific cooperation between Martinique and St Lucia was formalized in 
1987, with the signing of an agreement between France and St Lucia (Decree no. 90-678, 27 July 1990). This agreement was open-ended - there was no end date - therefore it is safe to assume that the provisions are still in force. There is, however, no available evidence to suggest that formal medical/healthcare cooperation was ever realized out of that agreement. Nonetheless, the UHM also provided dialysis for St Lucian patients and nursing training in various disciplines. More recent attempts to engage in a cooperative venture date back to $1995 / 6$, when a delegation including the Minister of Health and two pathologists visited Pierre Zobda Quitman University Hospital to discuss telemedicine between the two islands. Unfortunately, the signalling systems of the telecom networks of St Lucia (North American) and Martinique (European) were incompatible at that time. Nonetheless, cooperation between individual physicians has continued on a personal level, and Centre Hospitalier Universitaire La Meynard (University Hospital of Meynard) continues to be the primary referral point, as well as for emergency medical evacuations.

Beginning in 2007, the Réseau Périnatal de le Martinique (The Martiniquais perinatal networks) commenced working with paediatricians in St Lucia and Dominica, and several children benefitted from this programme until the European Union (EU) funding was exhausted. In 2009, the Regional Council and the UHM signed an agreement with the Government of St Lucia to provide specified assistance in respect of the new EU-funded hospital in St Lucia, which has still not been brought into service. Interestingly, in 2011, the Réseau Oncologie de la Martinique (The Martiniquais cancer networks) signed another accord with the Ministry of Health in Martinique.

Such cooperation is inevitable for cultural and geographic reasons (2). St Lucia's heritage is essentially French; the island changed hands between France and Britain fourteen times in 200 years, ending in 1813, where it remained a British colony until its independence in 1979. Martinique is only $40 \mathrm{~km}$ to the north of St Lucia, and the same creole language is spoken in both islands. What has been absent is a formalized framework which embraces all of the elements. There is no doubt that cooperation will become much easier if we became bilingual. In that regard, there is a creole language training programme for the French medical personnel conducted by the Institut de Langues at Rédoute in Martinique. This institute has indicated that English can also be taught. In St Lucia, assistance can be sought from the Alliance Française to teach French.

Recent developments on the political front have also highlighted the need for a structured regime of cooperation, following Martinique's acceptance as an associate member in the OECS and several other Anglo/Latin American regional organizations. St Lucia has also become a full member of the Organisation International de la Francophonie (OIF), and French is its second official language. Thus, together with Dominica, St Lucia represents the focal point for wider regional healthcare regimes, involving for instance, the University of the West Indies (UWI).

\section{Why set up an inter-regional medical cooperation?}

Today, healthcare cooperation is the most appropriate way to manage medical issues (3). The idea is that cooperation should not only involve education, culture, science and environment, but also the health sector which has the largest attractiveness potential in the region for the UHM. Approximately 10 to $15 \%$ of our admissions are overseas patients. Our goals are the following:

- to contribute to the development of medicine with mutual respect of each other's knowledge and working practice;

- to exchange and share competence and knowledge, including training courses, consultancy advice, audit, visiting doctors, conferences and video conferences;

- to share expertise and experience, especially in addressing similar problems;

- to promote medical research, sharing clinical research studies;

- to elaborate on therapeutic strategies like telephone information, advice for emergency and poisonings, allowing treatment of patients in their country of origin;

- to fight against professional isolation and

- to develop partnerships with colleagues in neighbouring countries.

\section{Persistent problems to be solved}

Several problems restrict the degree of cooperation which is achievable. The European Community's position and policies have to be clarified in regards to the major projects in the Caribbean basin. Agreements at the state level should be set up to definitively build health cooperation regarding the Dominican and St Lucian patients. Cooperation should include healthcare funding for the indigent, rapid responses in emergency situations, development of systems of privileged information exchange like telemedicine, facilitation of less complicated medical evacuations, improved accommodations for patients and their families, and initiation of common Caribbean research programmes. The collective medical cooperation should be preferred to any individual personal relation. Emergency healthcare training programmes should be developed and teaching proposals offered to practitioners in nearby universities. Consistently, this cooperation programme should be run in a manner which is mutually respectful and with the understanding of what cooperation actually entails.

\section{CONCLUSION}

In conclusion, the closer ties between the UHM and its regional partners will be beneficial to its development and helpful in facing new financial challenges. These new partnerships will stimulate progress in different areas of the UHM's competence. Currently, patients from surrounding countries are routinely admitted to the UHM in all 
departments of medicine. The inter-regional cooperation between the French departments of the Americas and all other Caribbean countries is essential for the implementation and improvement of healthcare. It is urgent for the Caribbean professionals to discuss the possibilities of developing common solid relationships in training, collective scientific research and continuous medical education.

\section{REFERENCES}

1. Drucker J, Quenel P. Nouveaux contextes et nouveaux enjeux pour la coopération sanitaire des DFA avec la région des Caraïbes. Bulletin de Veille Sanitaire 2011; (2): 1-17. Available from: file://C:/Users/ 10032252/Downloads/bvs_ag_2011_02.pdf

2. Samuels TA, Guell C, Legetic B, Unwin N. Policy initiatives, culture and the prevention and control of chronic non-communicable diseases (NCDs) in the Caribbean. Ethno Health 2012; 17: 631-49.

3. Ghazwan B. International cooperation to promote advances in medicine. Ann Thorac Med 2008; 3: 79-81.
Submitted 17 Feb 2014

Accepted 27 Feb 2014

Published 15 Apr 2014

Online: http://myspot.mona.uwi.edu/wimjopen/article/57

(c) Resiere et al 2014.

This is an open access article made freely available under Creative Commons Attribution 4.0 International (CC BY 4.0). Users are free to share, copy and adapt this work as long as the copyright holder (author) is appropriately and correctly credited. See http://creativecom mons.org/licences/by/4.0/deed.en_us for more information. 